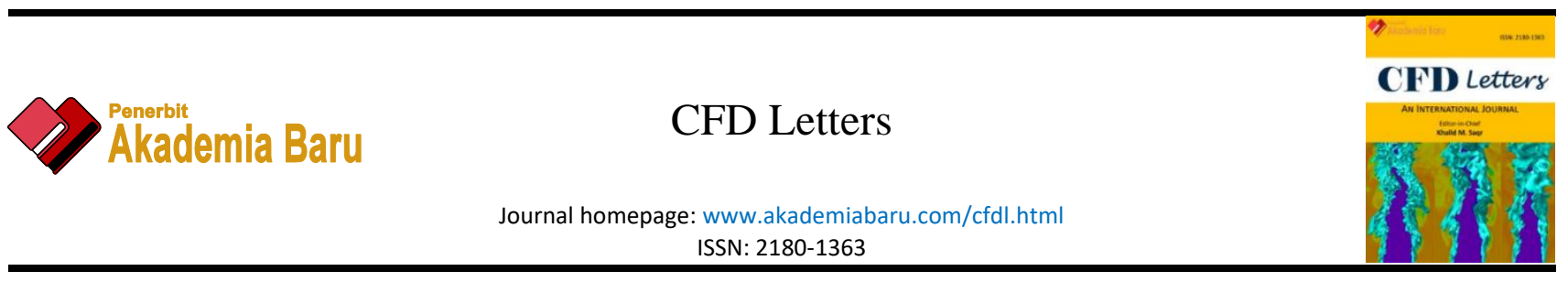

\title{
Influence of Actuator Nozzle Angle on the Flow Characteristics in Pressurized-Metered Dose Inhaler Using CFD
}

\author{
Muhammad Faqhrurrazi Abd Rahman ${ }^{1,}{ }^{*}$, Nor Zelawati Asmuin ${ }^{1}$, Ishkrizat Taib ${ }^{1}$, Mohamad Nur \\ Hidayat Mat ${ }^{1}$, Riyadhthusollehan Khairulfuaad ${ }^{1}$ \\ 1 Department of Thermofluids Engineering, Faculty of Mechanical and Manufacturing Engineering, Universiti Tun Hussein Onn, 86400 Parit Raja, \\ Johor, Malaysia
}

\section{ARTICLE INFO}

\section{Article history:}

Received 21 April 2020

Received in revised form 18 June 2020

Accepted 25 June 2020

Available online 30 June 2020

Keywords:

Alveolar; angle; pressurized metered

dose inhalers; simulation

\section{ABSTRACT}

\begin{abstract}
Pressurized metered dose inhalers (pMDIs) are often used for the treatment of asthma and chronic obstructive pulmonary disease. This device is easy to carry, highly effective and extremely safe, allowing reliable, consistent dosage delivery, metered dose inhalers are the inhalation devices that doctors and patients can readily select from around the world. This pMDI inhaler system has a problem which is the particle does not penetrate into the alveolar. ANSYS Fluent Version 19.2 was used to find the best angle of the actuator nozzle by parametric analysis. Standard K-epsilon was used as the turbulence model with enhanced wall treatment function. Discrete phase model (DPM) was applied to represent the particle flow. The result shows the best actuator nozzle angle is 120-degree which affects the maximum magnitude of particle velocity.
\end{abstract}

Copyright @ 2020 PENERBIT AKADEMIA BARU - All rights reserved

\section{Introduction}

Inhalation aerosols called Pressurized Metered-Dose Inhalers (pMDI) can provide drug delivery efficiency in the respiratory system of the human airways. The PMDI is easy to use and can deliver in an atomized form [1]. In addition, a dose of medication is set and can be supplied with each actuation [2]. In medication treatment for inhalation, there are three (3) types of inhaler products such as nebulizers, dry powder inhalers and pressurized metered-dose inhalers (pMDI) [3]. These devices may generate solutions that contain drugs, suspend solid drug particles in a gas or dry powder solid particles [4]. In 1998, the pMDI inhaler boost from 440 million unit to 800 million units in 2000 and produce more than $80 \%$ of the medicine therapy devices marketed worldwide in 2004 [5]. The efficiency of pMDI has steadily increased since chlorofluorocarbon (CFC) was banned by the United Nations because of its harmful effects on the ozone layer [6]. The new era for pMDI began with the launch of hydrofluoroalkane (HFA) as a new propellant that replace chlorofluorocarbon (CFC) [7], these improvements result in an enormous achievement for pMDI because HFA propellants do not

\footnotetext{
* Corresponding author.

E-mail address: hd170038@siswa.uthm.edu.my (Muhammad Faqhrurrazi Abd Rahman)
} 
have ozone-depleting and environmentally friendly properties [8]. From the previous researcher Leach et al., [9] shows the difference between HFA and CFC propellant in dose-reaching deposition in the respiratory tract. It is shown that the HFA propellant can produce small particle size and the dose can enter the lung by $40 \%$ compared to CFC, only $20 \%$ of the dose can reach the lung [9]. Kleinstreuer et al., [10] is one of the leading researchers researching HFA-pMDI and CFC-pMDI numerically in the oral airway model. In his research, 2000 particles were used in the oral airway model, $150 \mathrm{~m} / \mathrm{s}$ for initial velocity, the cone angle is $35^{\circ}$, and Dunbar et al., [22] obtained the size distribution. The result was enormous, i.e. the droplet inhaled entered the lung for HFA-pMDI is $47 \%$ and the droplet inhaled for CFC-pMDI is 23\% [10]. Drug formulation that is stored in the device can be replaced at any time by a disposable canister [11]. There are five (5) types of the main component that can be found in the pMDI inhaler device, which is the metering chamber, the formulation canister, the container, the propellant and the actuator of the nozzle. The pMDI schematic crosssection are shown in Figure 1 [12].

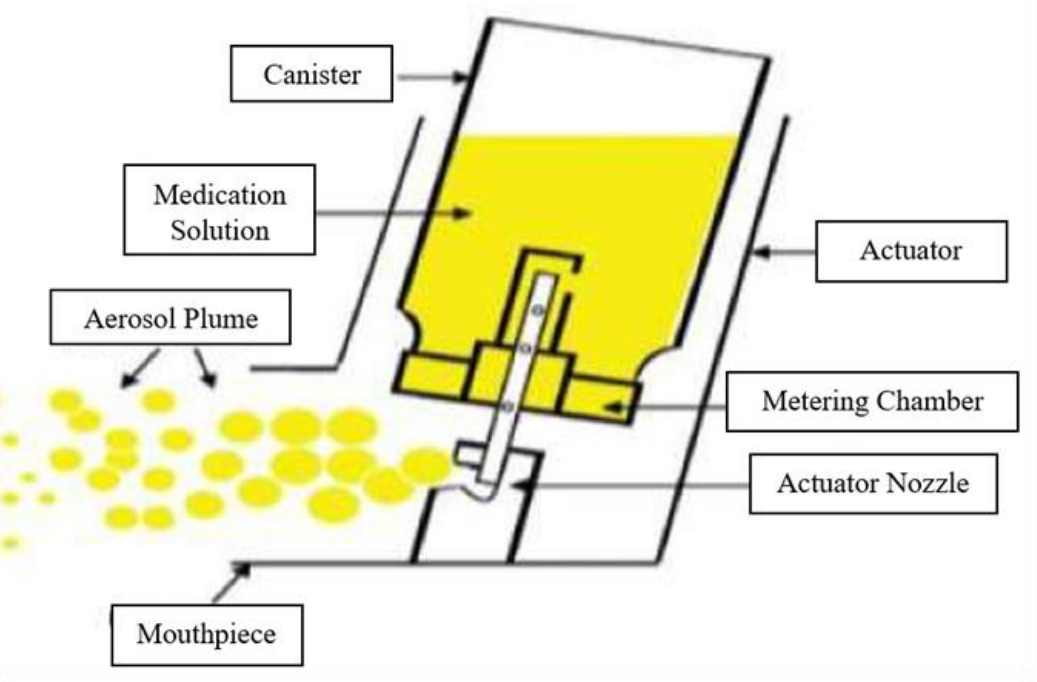

Fig. 1. pMDI schematic cross-section [12]

By using the HFA as a propellant, the aerosol plume can be supplied at a higher temperature with a lower impact force of $25.5 \mathrm{mN}$ compared to the $95.4 \mathrm{mN}$ CFC propellant [13]. Ahmed Fadl et al., [14] shows in their journal that the mouthpiece entrance angles can influence the drug particles penetration. The various parameters are being tested, such as flow rate $(30,60$ and $90 \mathrm{~L} / \mathrm{min})$, angle of entrances $\left(0^{\circ}, 10^{\circ}, 20^{\circ}, 30^{\circ}\right.$ and $\left.40^{\circ}\right)$ and mouthpiece diameters $(16 \mathrm{~mm}$ and $20 \mathrm{~mm}$ ) are being study. The result shows that the entrance angle $30^{\circ}$ has the highest penetration compared to the other angle for $16 \mathrm{~mm}$ diameter of the mouthpiece with flow rate $(30,60$ and $90 \mathrm{~L} / \mathrm{min})$. For $20 \mathrm{~mm}$ diameter of mouthpiece with flow rate $(30,60$ and $90 \mathrm{~L} / \mathrm{min})$, the $30^{\circ}$ and $20^{\circ}$ has the maximum penetration [14]. Through reducing the diameter of the orifice from 0.22 to $0.14 \mathrm{~mm}$, the plume length from $0.5 \mathrm{~s}$ can be increased to $1.2 \mathrm{~s}$ and the actuator angle decreased [15]. Experimental and numerical results showed that increasing the angle of inclination would boost the output of the pipe to a maximum value of $90^{\circ}$ [16]. The spray deposition rate can be reduced by increasing the initial spray velocity over the range of $100-150 \mathrm{~m} / \mathrm{s}$ and by increasing the range of $2^{\circ}-10^{\circ}$ for the spray cone angle [17].

Previous researcher Cheng et al., [18] reported that the spray angle for propellant HFA and CFC are $35^{\circ}$, nevertheless, the Oliveira et al., [19] suggest that the HFA-pMDI angle is $10^{\circ}$ and $17^{\circ}$. Crosland et al., [20] experimental particle image velocimetry (PIV) shows that the spray cone angle 
was unstable and varied up to $8^{\circ}$ during the first $100 \mathrm{msec}$ of the transient spray case. No researcher investigated the effect of the actuator angle on its performance in terms of the magnitude of particle velocity. Hence, this work is aimed at examining various parametric designs for actuator nozzle consistent with this research objective.

\section{Methodology}

\subsection{Geometrical Modelling}

The isometric section view of pMDI inhaler device was design by using SolidWorks 2016 are shown in Figure 2(a) while the hollow part of the nozzle (yellow color) is presented in Figure 2(b) and the schematic of an internal parts in the actuator nozzle is shown in Figure 2(c). Geometrical representation pMDI Inhaler dimension was referred from previous literature on the pMDI Sprays: theory, experiment and numerical simulation [21]. Based on the simulation results performed by Ricardo F. Oliveira et al., [19] it is possible to determine the base design diameter for pMDI units, the diameter of the orifice being $0.49 \mathrm{~mm}$, the angle of the actuator being $165^{\circ}$ and the length of the orifice being $1.50 \mathrm{~mm}$. A parameter was used to define the geometry of the actuator nozzle was orifice diameter (D), length of the orifice $(L)$ and angle of the actuator $(\theta)$ that shown in Figure 2(c).

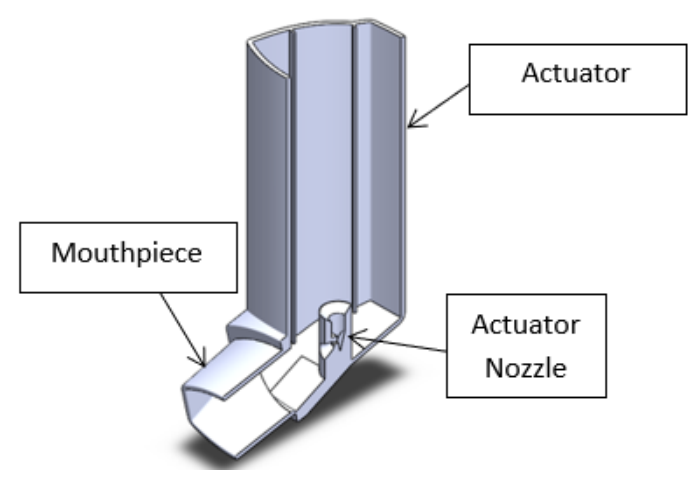

(a)

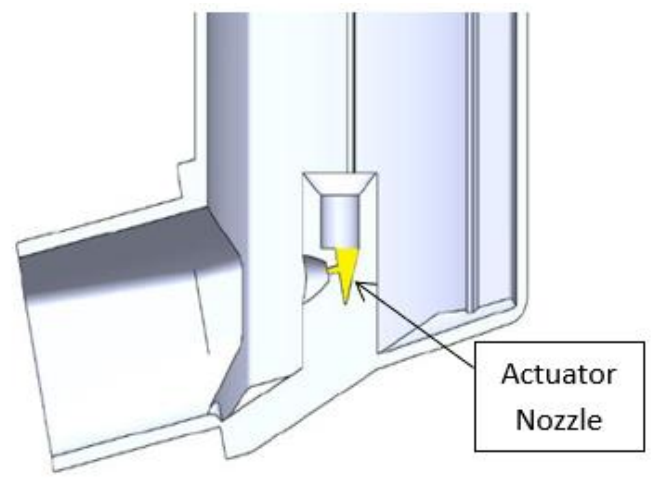

(b)

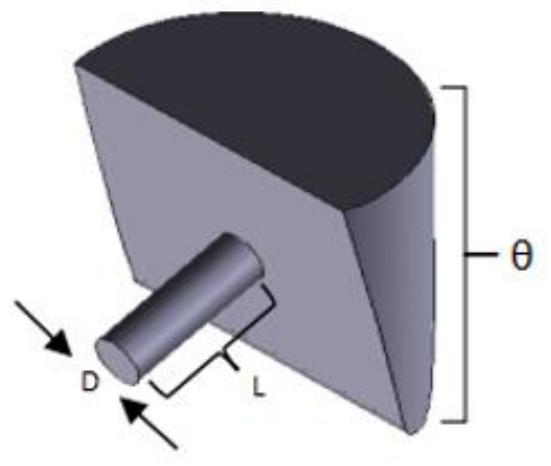

(c)

Fig. 2. Geometrical modelling of pMDI inhaler device. (a) Isometric section view of pMDI inhaler device, (b) The hollow part of the nozzle (yellow color), (c) Schematic diagram of internal parts in the actuator nozzle

\subsection{Grid Independent Test of Actuator Nozzle inside the pMDI Device}

A pMDI inhaler model devices was redesigned from the previous literature study on pMDI Sprays: theory, experiment and numerical simulation [21]. By using the Grid-independent test, the model's precision can be maintained and it is compulsory. The Grid-independent test value must remain as 
low as possible in order to maintain its accuracy. Nonetheless, in this GID series, the coarse, medium and fines meshed can be generated and the solution can shift between medium and fine mesh. Grid independent test for actuator nozzle are shown in Table 1. There are nine (9) GID tests performed. The best GID is based on the lower skewness mesh metric value and the higher orthogonal mesh metric. It shows that number three (3) meets the selection of criteria for the GID. The GID already selected by selecting number three (3) for further analysis of simulation.

Table 1

Grid independent test for based model

\begin{tabular}{lllll}
\hline No & Number of Nodes & Number of Elements & Skewness Mesh Metric & Orthogonal Mesh Metric \\
\hline 1 & 336534 & 513533 & 0.9455 & 0.9530 \\
2 & 351646 & 460923 & 0.9171 & 0.9143 \\
3 & 313697 & 582244 & 0.8560 & 0.9926 \\
4 & 342386 & 518691 & 0.9440 & 0.9544 \\
5 & 301486 & 462832 & 0.8639 & 0.9889 \\
6 & 317223 & 325814 & 0.9409 & 0.8891 \\
7 & 312259 & 389231 & 0.9417 & 0.8143 \\
8 & 398541 & 458975 & 0.9254 & 0.8456 \\
9 & 348948 & 418618 & 0.8896 & 0.9236 \\
\hline
\end{tabular}

The main properties of drug formulation for propellant-HFA 134a, ethanol and salbutamol involved in this study a listed in Table 2:

Table 2

Property of drug formulation [21]

\begin{tabular}{llll}
\hline Properties & HFA-134a & Ethanol & Salbutamol \\
\hline Density $(\mathrm{kg} / \mathrm{m3})$ & 1311 & 790 & 1230 \\
Specific Heat (j/kg-k) & 982 & 2470 & - \\
Thermal Conductivity (w/m-k) & 0.0857 & 0.182 & - \\
Viscosity (kg/m-s) & 0.000211 & 0.0012 & - \\
Molecular Weight (kg/kmol) & 102.032 & 46.07 & 337.387 \\
\hline
\end{tabular}

\subsection{Meshing of Actuator Nozzle Inside the pMDI Device}

The below dimension meshed model that be designed in mesh mode of Ansys components systems are shown in Figure 3. The infinite number of particles in the meshing process can be transformed into the finite number of particles. The mandatory measuring cell must be carried out with high efficiency and accuracy. The refining mesh (used in smaller cells) can be set up for a large solution gradient and fine geometric data, but the coarse mesh (used in giant cells) can be used elsewhere. To achieve a good mesh quality, it is necessary to maintain the accuracy and stability of the solution. In the ANSYS, there are four operation mesh mode can be done. The process was beginning with specifying the global mesh setting, inserting a local mesh setting, generating the mesh and checking mesh quality [22-23]. By using proximity and curvature, the curve object (cylinder) and square object (box) can be pick as the convergent segment. To select the meshing size, the Grid Independent Test was required. Meshed model of the nozzle is shown in Figure 3(a) and details view for the angle of actuator in the actuator nozzle is presented in Figure 3(b). 


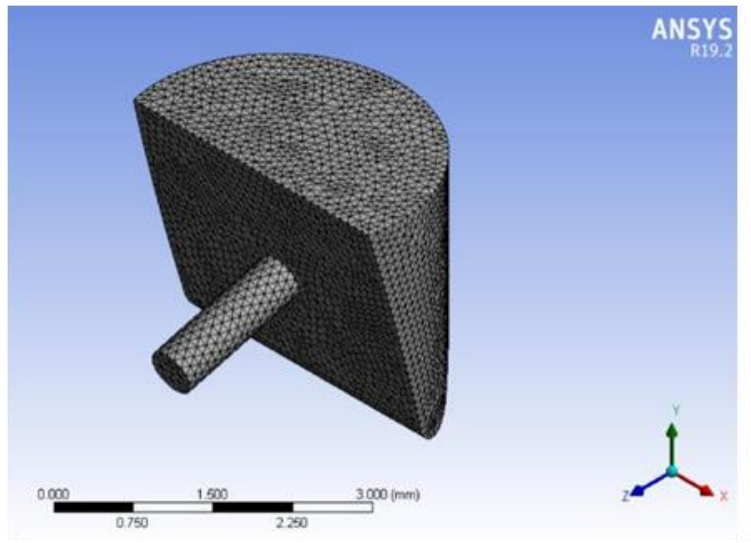

(a)

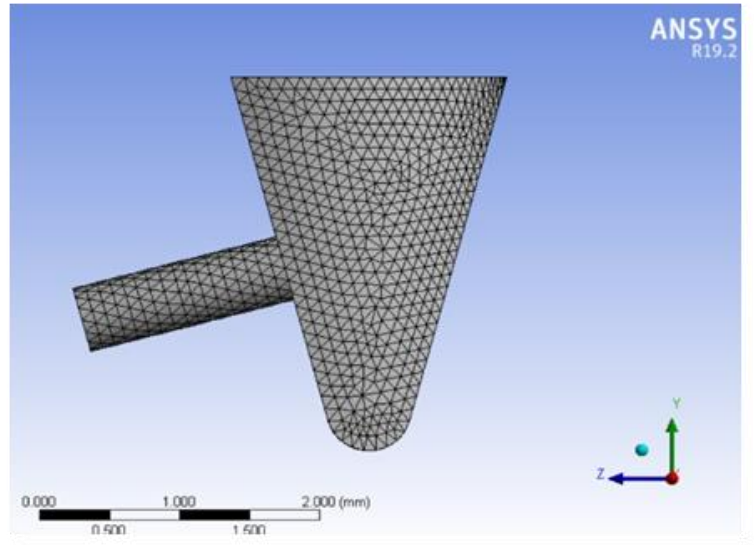

(b)

Fig. 3. Meshing process for internal parts in the actuator nozzle. (a) Meshed model of the nozzle (b) details view for the angle of actuator in the actuator nozzle

\subsection{CFD Simulation Method for Actuator Nozzle Inside the pMDI Device}

The purpose of this simulation is to illustrate the configuration parameters better suited to the real-life case of a pMDI inhaler spray using commercially available CFD software, such as ANSYS ${ }^{\circledR}$ Fluent version 19.2. Rosin-Rammler was selected as the diameter distribution in the Discrete phase model. The CFD solver accepts this type of distribution by inserting its parameters in Table 3 [24].

Table 3

Property of Particle Diameter [22]

\begin{tabular}{ll}
\hline Parameter & Value \\
\hline Diameter distribution & Rosin-Rammler \\
Minimum diameter $(\mu \mathrm{m})$ & 1.22 \\
Maximum diameter $(\mu \mathrm{m})$ & 49.50 \\
Mean diameter $(\mu \mathrm{m})$ & 16.54 \\
Spread parameter & 1.86 \\
\hline
\end{tabular}

The drug amount of puff $(100 \mu \mathrm{g})$ can be used and divided by the duration of a puff $(0.1 \mathrm{~s})$. The spray flow rate can be determined using the puff quantity and puff duration. The solver spray configuration parameters are shown in Table 4 below.

Table 4

Property of Spray Configuration

\begin{tabular}{ll}
\hline Parameter & Value \\
\hline Spray type & Solid-cone $[9,18]$ \\
Angle $\left(^{\circ}\right)$ & $10[21]$ \\
Velocity $(\mathrm{m} / \mathrm{s})$ & $100[9]$ \\
Radius $(\mathrm{m})$ & $0.00025[25,19]$ \\
Flow rate $(\mathrm{kg} / \mathrm{s})$ & $1 \mathrm{e}^{-6}[21]$ \\
\hline
\end{tabular}

Parameters for the discrete phase model have already been evaluated in different configurations and those described here seemed best suited for simulation purposes. The inject time step size (s) use for this DPM are particle time step. The unsteady particle tracking was used because of the limited period time (0.1s) for the injection was occur. The spherical type was used as the drag law and this simulation activates the two-way coupling turbulence [25]. 


\subsection{Verification of Actuator Nozzle Inside the pMDI Device}

In this verification system of pMDI devices, four (4) parameters were selected from the previous literature analysis as shown in Table 5 , which is particle velocity magnitude, velocity magnitude, air temperature and HFA mass. The reference model for verification was refer from the pMDI Sprays: theory, experiment and numerical simulation [21] The previous model was simulated using version 14.0 of Ansys Fluent. On the other hand, this analysis would use Ansys Fluent version 19.2 to do the simulation. The highest relative error for geometric modeling shown in the table below is $6.2 \%$. For the numerical simulation, the average limit for comparing two (2) simulated models is below $10 \%$, according to Goswami, Kumar and Munshi 2015 [26]. As the maximum value is below the average limit and the geometric simulation is appropriate, the further simulation can be performed.

Table 5

Verification of based model geometry

\begin{tabular}{lllll}
\hline $\begin{array}{l}\text { Velocity } \\
\text { Inlet }(\mathrm{m} / \mathrm{s})\end{array}$ & Variable Parameters & $\begin{array}{l}\text { Result by Fluent 14.0 } \\
{[27]}\end{array}$ & $\begin{array}{l}\text { Result by Fluent } \\
19.2\end{array}$ & $\begin{array}{l}\text { Relative Error } \\
(\%)\end{array}$ \\
\hline 100 & Particle Velocity Magnitude $(\mathrm{m} / \mathrm{s})$ & 29.298 & 28.421 & 3.6 \\
& Velocity Magnitude $(\mathrm{m} / \mathrm{s})$ & 10.29 & 10.91 & 6.0 \\
& Air Temperature $(\mathrm{K})$ & 293.15 & 293.01 & 0.05 \\
& HFA Mass Fraction & 0.0029 & 0.0027 & 6.2 \\
\hline
\end{tabular}

\section{Results}

\subsection{Qualitative Analysis of Flow characteristic of Actuator Nozzle along the Axis of Center-line}

The axis of center-line inside nozzle is presented in Figure 4, while the flow characteristic in term of particle mass concentration, eddy viscosity, pressure, turbulent eddy dissipation, turbulent kinetic energy and velocity development along the nozzle center-line are presented in Figure $5 . \mathrm{X}$ axis $(\mathrm{m})$ are represented direction of the center-line inside the nozzle.

\section{a) Particle mass concentration}

The concentration of particle mass against average position along the center-line $\mathrm{x}$ axis is shown in Figure 5(a). Particle mass concentration describes the distribution of drugs along the center-line of the orifice. The result was taken from the inlet to outlet of the orifice that represent the axis of the center-line. The result shows that the graph pattern increased in the particles mass concentration inside the center-line of the orifice when the difference angle was changed. Another significant result shows that the angle of 130-degree gives the lowest value of particle mass concentration along the center-line axis from the remainder. The rising concentration of particles mass is due to collisions between particles in actuator nozzle and along the center-line axis nozzle.

\section{b) Eddy viscosity}

The graph of eddy viscosity versus the position of $x$ axis along the center-line was display in Figure $5(b)$. With the increment of the angle of actuator nozzle and position along the center-line of the orifice as presented in Figure $5(\mathrm{~b})$, the overall trends for the eddy viscosity also increased. The result shows that angle of 120-degree give the highest value of eddy viscosity from the rest. It is proved that narrow angle of the actuator nozzle can generate highest particle flow development inside the orifice. 


\section{c) Pressure}

The result pressure against the average position along the $x$ axis of center-line was displays in graph Figure 5(c). The pressure of particles represents the drug distribution along the orifice centerline. The increased angle of the actuator nozzle can increase the pressure generally. From the graph, the results show that the pattern of the graph slowly decreased before the position of $-0.00010 \mathrm{~m}$ and steeply decreased after that. In point of fact, the data shows that the angle of 150-degree and 125-degree give the highest and lowest value of pressure respectively. Its is shows that the wider angle of the actuator nozzle can increased the pressure compared to the narrow angle.

\section{d) Turbulence eddy dissipation}

The graph in Figure 5(d) displays the turbulence eddy dissipation against the position along the $x$ axis of the center-line. The graph shows the increase in trend before the $-0.00002 \mathrm{~m}$ position and then start to decrease after the point. By reducing the angle of the actuator nozzle can rising the turbulence eddy dissipation as shown in graph where the narrow angle tested is 120-degree. The highest value for turbulence eddy dissipation in the graph is 130-degree. The same trend was observed by Syazwan et al., [28] it is shows that reducing the angle of actuator nozzle can increased the flow velocity. This result can be affected the development of the turbulence flow which is turbulence eddy dissipation.

\section{e) Turbulence kinetic energy}

Turbulence kinetic energy against the position along the $x$ axis of the center-line is presented in Figure 5(e). Generally, the turbulence kinetic energy trend starts to increase in the range between 0.00010 to -0.000015 and decline afterward. The highest value for the turbulence kinetic energy is 150-degree and the lowest is 125-degree. Increasing the angle of the actuator nozzle can increasing the value of the turbulence kinetic energy. By referring to graph in Figure 5(b), particle mass concentration increased with increment of the position. Thus, this cause more particle collisions to each other and subsequently create turbulence kinetic energy.

\section{f) Velocity}

The graph in Figure 5(f) displays the velocity against the position along the $x$ axis of the centerline. The velocity shows increasing in trends against position ranging from -0.00010 to -0.00002 and decline after that range. Another significant result shows that the gradient of angle 125-degree increased sharply along the axis of the center-line from the rest. Accordance to the graph Figure 5(d), the statement told that the narrow angle can produce highest flow velocity inside the actuator orifice compared to the wider one. Therefore, the narrow angle can reduce the pressure and rising the velocity. 


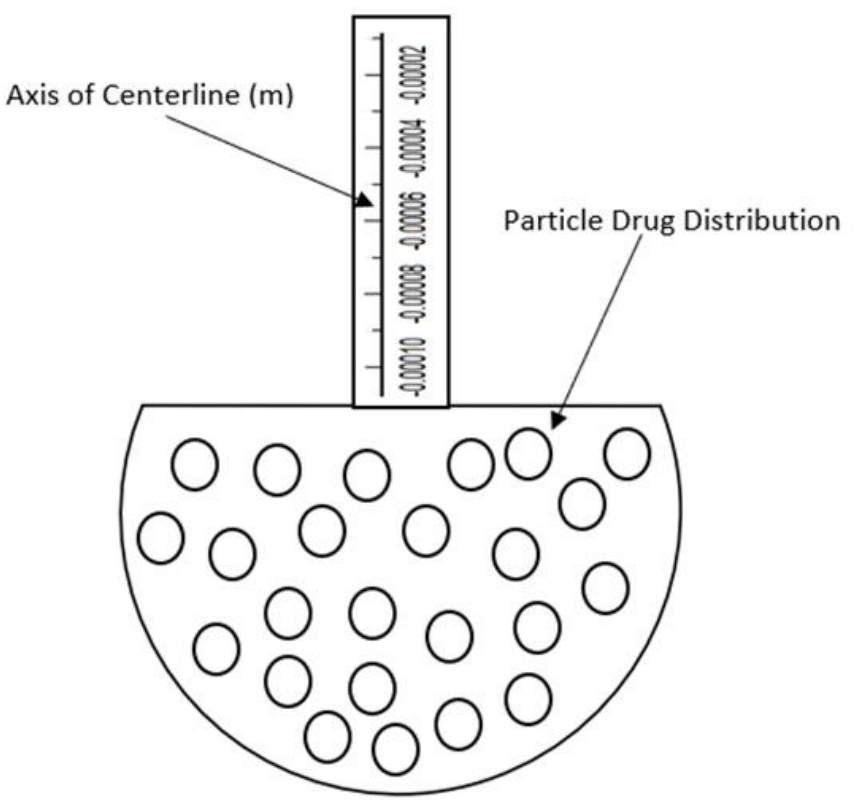

Fig. 4. Axis of center-line inside the actuator nozzle

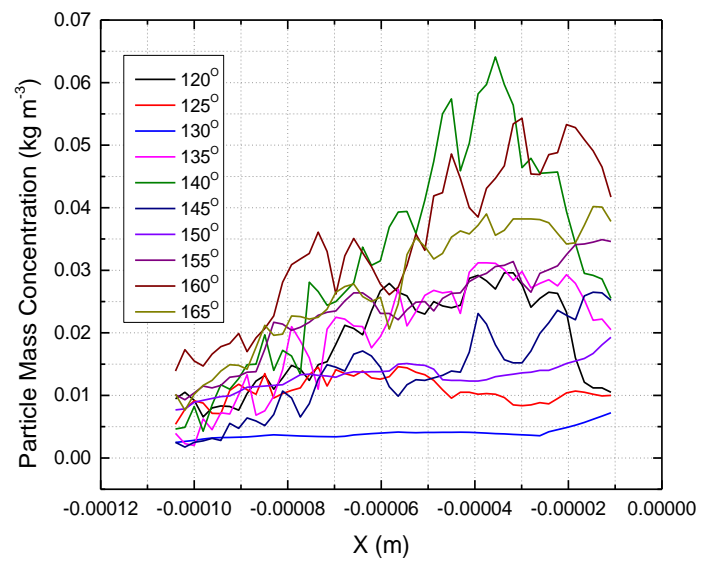

(a)

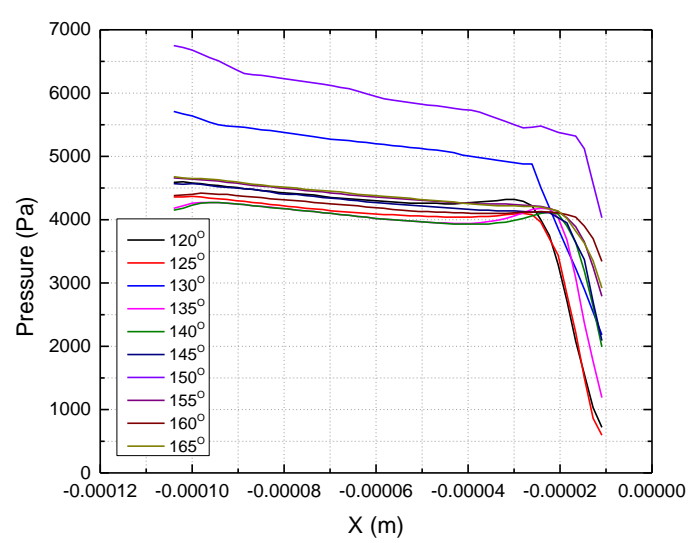

(c)

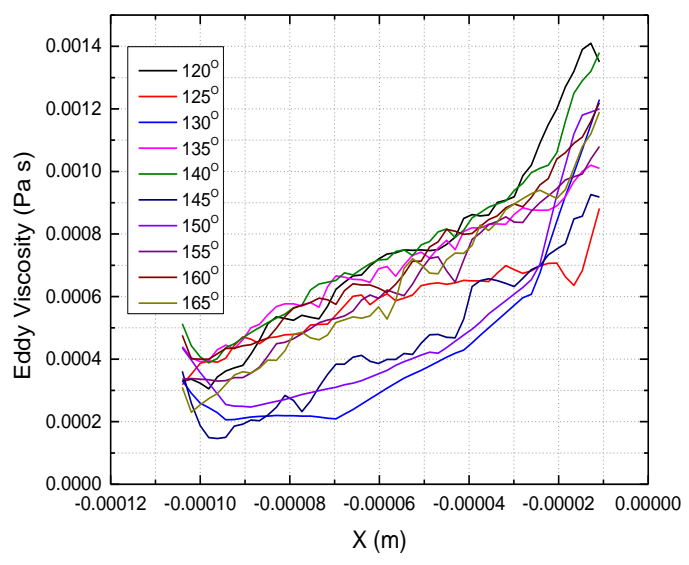

(b)

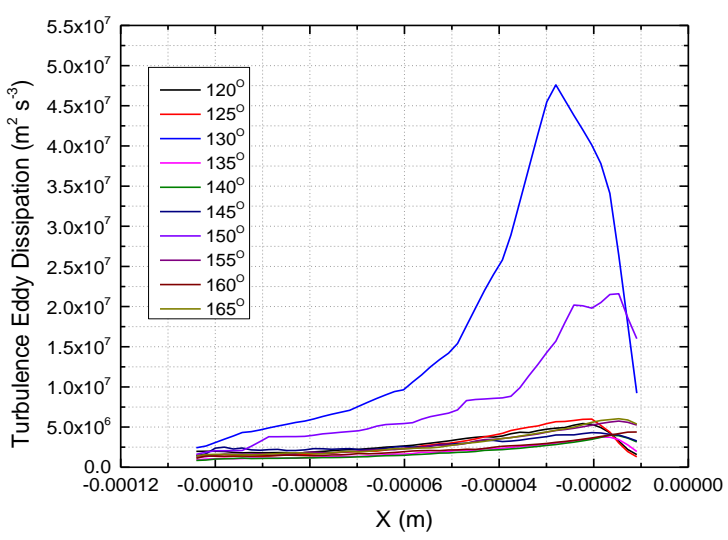

(d) 


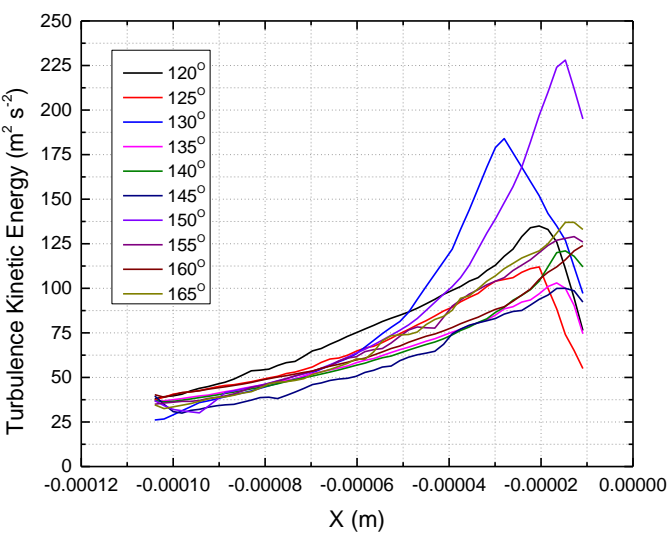

(e)

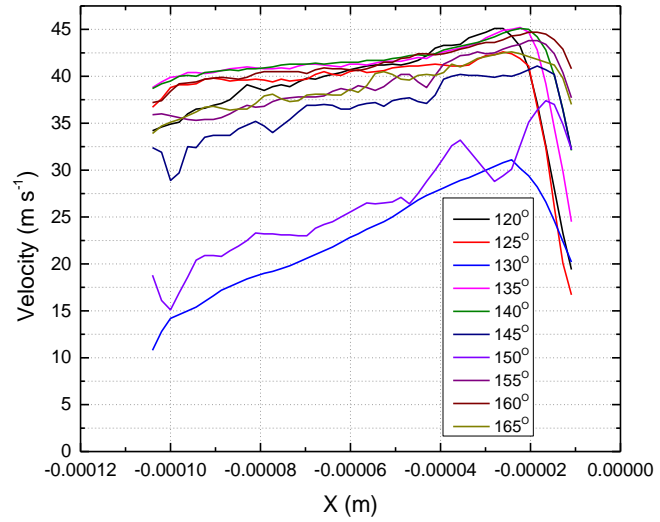

(f)

Fig. 5. Flow characteristic angle of actuator nozzle along axis of center-line (a) particle mass concentration along the center-line (b) eddy viscosity (c) pressure (d) turbulence eddy dissipation (e) turbulence kinetic energy (f) velocity

\subsection{Qualitative Analysis of Particle Velocity Magnitude on Actuator Nozzle}

The particle velocity magnitude on different angle of actuator nozzle is shown in Figure 6 . The simulation on the particle velocity magnitude is one of the critical parameters to recognize the flow inside the actuator nozzle. The result shows that the narrow angle produce highest velocity magnitude and lesser particle can be generated from the actuator nozzle. The 120-degree of actuator nozzle as shown in Figure 6(a) has the highest velocity while the lowest velocity of actuator nozzle is 150-degrees as shown in Figure 6(j). These values can be seen in color contour legend.

(a)

(b)

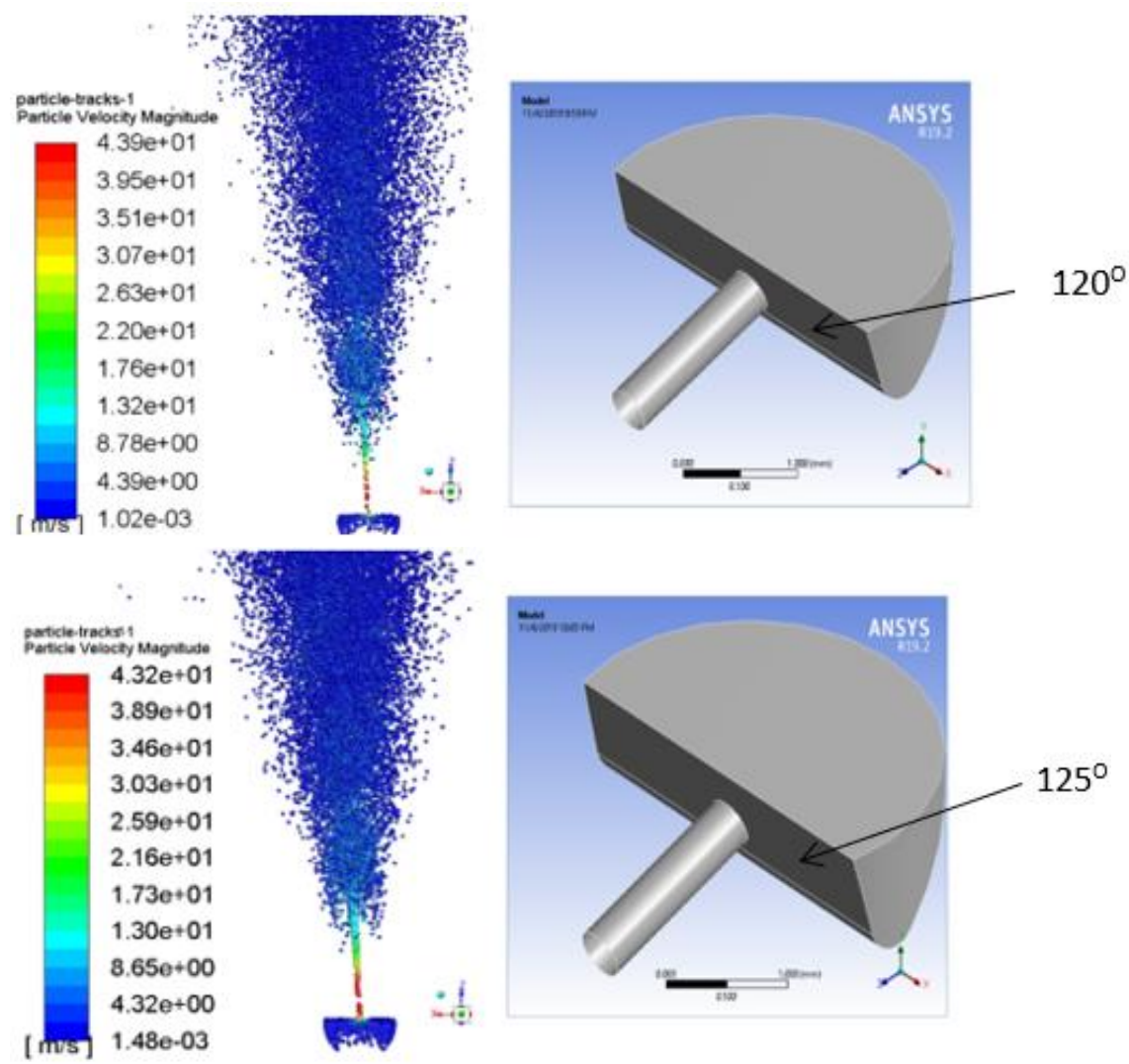


(c)
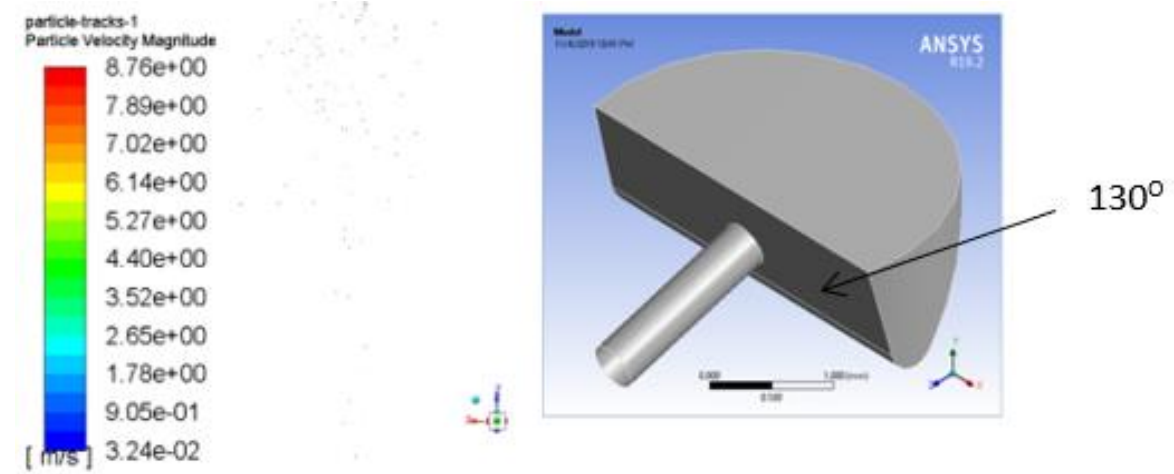

(d)

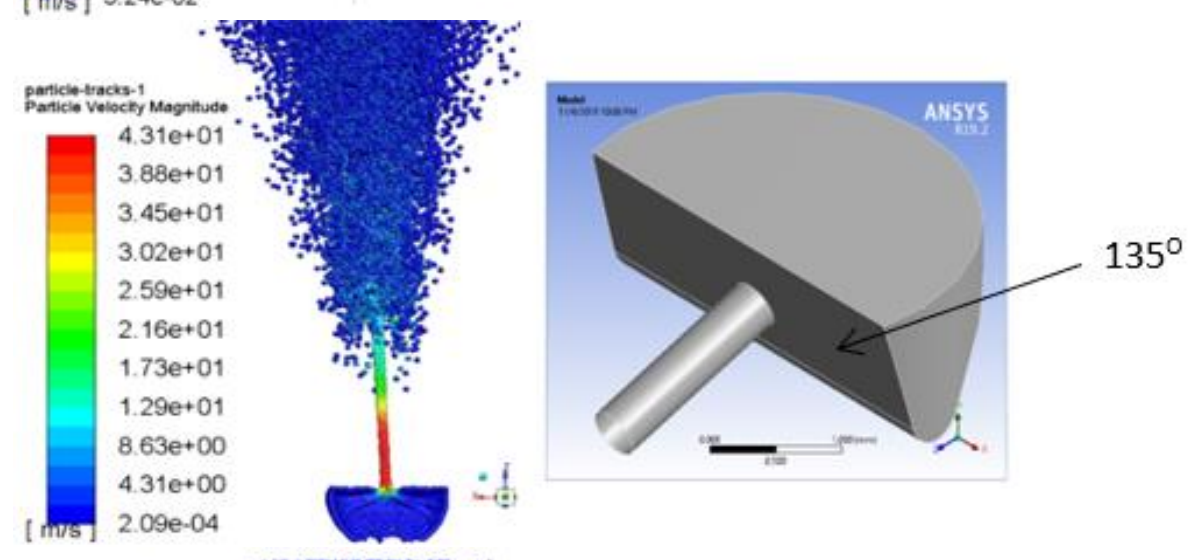

(e)

$$
\text { particle trackss }
$$
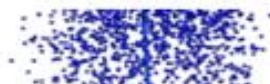

Particlo Velocty Magnatude

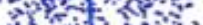

$4.26 \mathrm{e}+01$

$3.83 e+01$

3. $40 \mathrm{e}+01$

2. $98 \mathrm{e}+01$

$2.55 \mathrm{e}+01$

2. $13 \mathrm{e}+01$

1.70e+01

$1.28 \mathrm{e}+01$

$8.51 \mathrm{e}+00$

$4.26 \mathrm{e}+00$

[ m/s] 8.11e-04
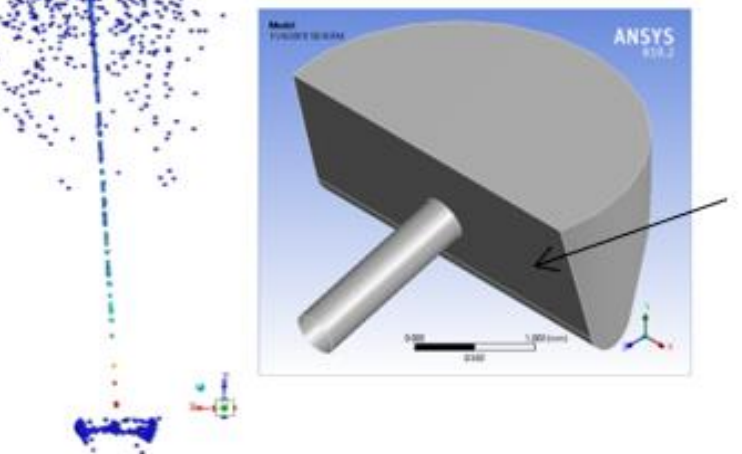

$140^{\circ}$

perticle-tracks-1

Magnitude $6.91 \mathrm{e}+00$ $6.22 \mathrm{e}+00$

$5.53 \mathrm{e}+00$

(f)

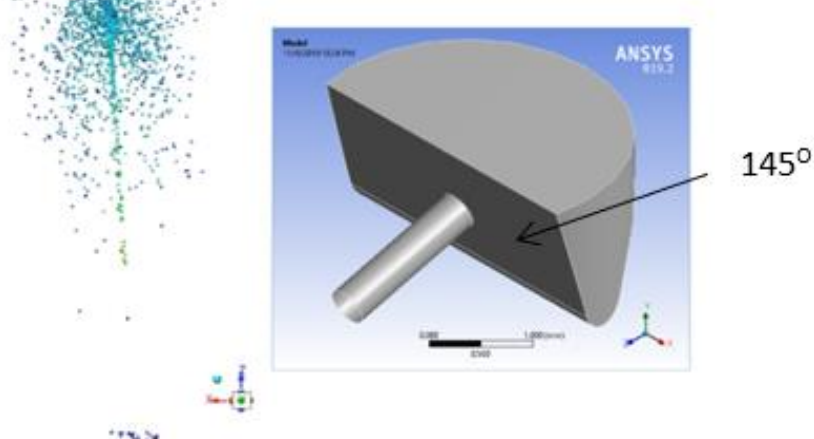


(g)
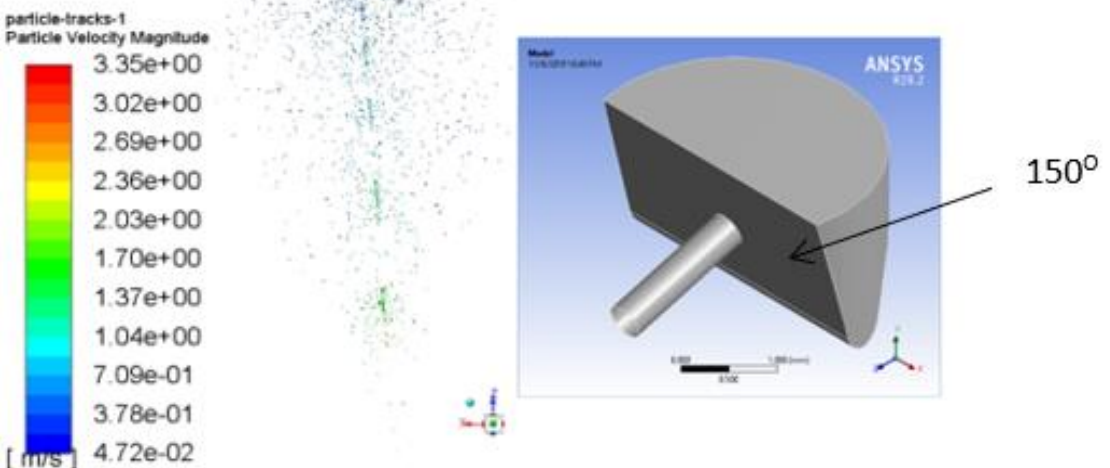

(h)
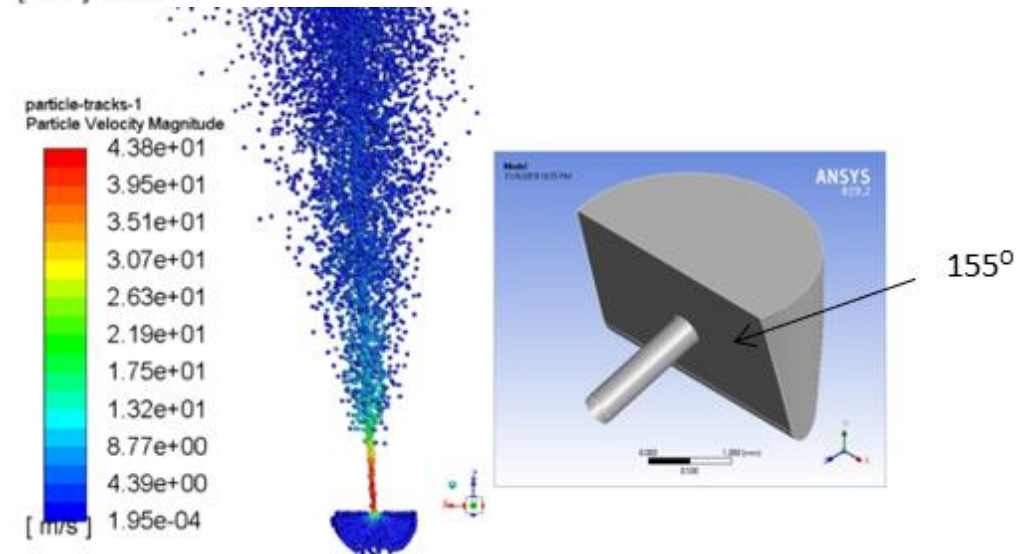

(i)

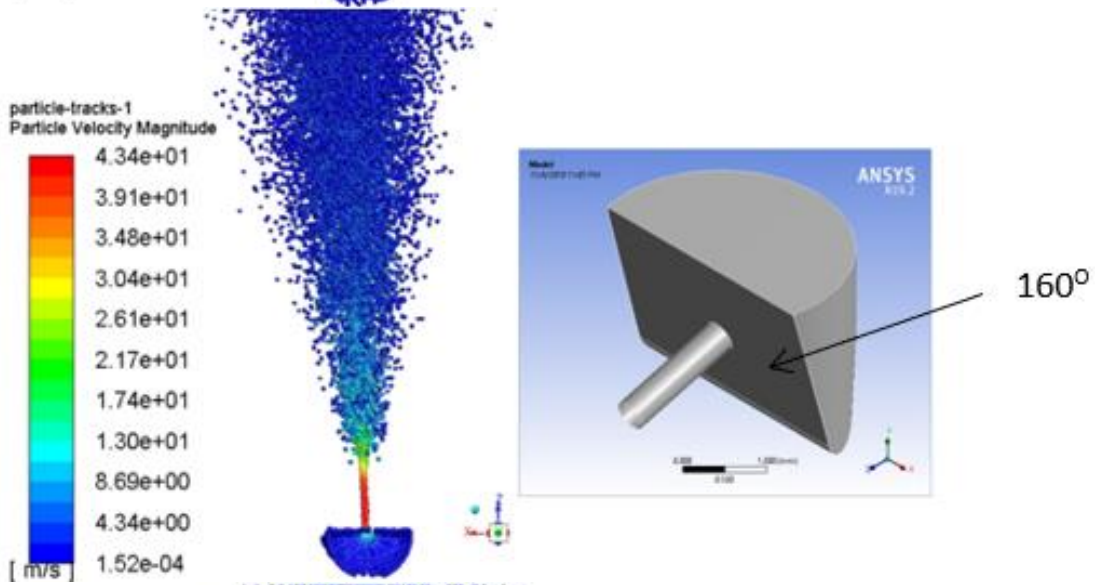

particie-tracks-1
Particle Velocity Magntud
$2.87 e+01$

$2.58 \mathrm{e}+01$

$2.29 \mathrm{e}+01$

$2.01 e+01$

$1.72 \mathrm{e}+01$

$1.43 e+01$

$1.15 \mathrm{e}+01$

$8.61 \mathrm{e}+00$

$5.74 \mathrm{e}+00$

$287 \mathrm{e}+00$

$5.13 e-03$

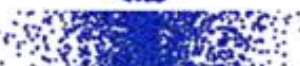

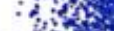

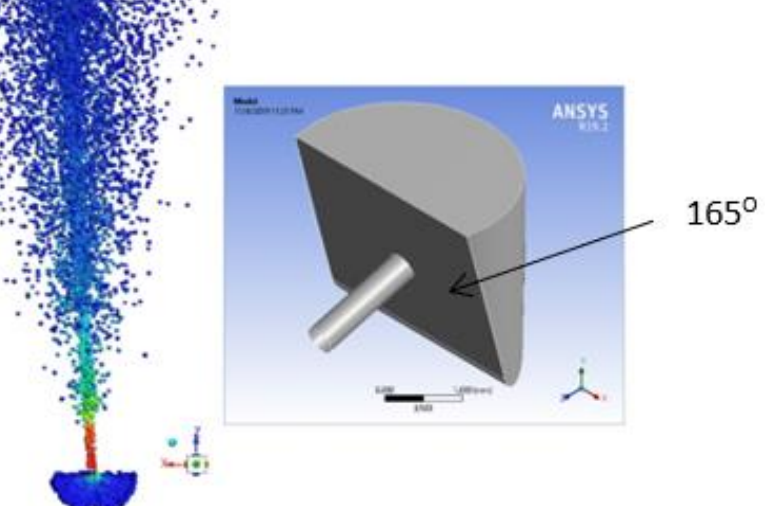

Fig. 6. Particle velocity magnitude on different angle of the actuator nozzle. (a) 120degree, (b) 125-degree, (c) 130-degree, (d) 135-degree, (e) 140-degree, (f) 145-degree, (g) 150-degree, (h) 155-degree, (i) 160-degree, (j) 165-degree 


\section{Conclusions}

The characteristics for particle flow in the actuator nozzle was analyzed by using the standard wall of the K-epsilon function and Discrete particle model (DPM) mode. In the analysis under way, a 3-Dimensional (3D) simulation has been carried out for tenth (10) different angle of the actuator nozzle. After some parametric analyzes, it was found that 120-degree was the highest particle velocity compared to others. Furthermore, result shows that the 120 -degree angle can give the highest turbulence kinetic energy that resulted in the lowest pressure and the highest velocity development along the actuator orifice cavity as presented in section 3.1. The highest particle velocity magnitude can possibly make the drug reach the alveolar. Furthermore, Computational Fluid Dynamic (CFD) simulation is one of the best tools to provide a marvelous understanding of the flow feature and particles inside the actuator nozzle. It can also provide a good indicator of changing particle flow with varying color contours. In this analysis the simulation focuses only on the angle of the actuator, without relying on other parameters. Therefore, certain parameters such as the length of the orifice can be considered for simulation research in future work.

\section{Acknowledgement}

The author would like to acknowledge the Centre of Graduate Studies, Universiti Tun Hussein Onn Malaysia and Postgraduate Research Grant (GPPS) H03O for sponsoring this project.

\section{References}

[1] Smyth, Hugh DC. "The influence of formulation variables on the performance of alternative propellant-driven metered dose inhalers." Advanced drug delivery reviews 55, no. 7 (2003): 807-828. https://doi.org/10.1016/s0169-409x(03)00079-6

[2] Lavorini, Federico. "The challenge of delivering therapeutic aerosols to asthma patients." ISRN allergy 2013 (2013). https://doi.org/10.1155/2013/102418

[3] Dolovich, Myrna B., Richard C. Ahrens, Dean R. Hess, Paula Anderson, Rajiv Dhand, Joseph L. Rau, Gerald C. Smaldone, and Gordon Guyatt. "Device selection and outcomes of aerosol therapy: evidence-based guidelines: American College of Chest Physicians/American College of Asthma, Allergy, and Immunology." Chest 127, no. 1 (2005): 335-371. https://doi.org/10.1378/chest.127.1.335

[4] Myrdal, Paul B., Poonam Sheth, and Stephen W. Stein. "Advances in metered dose inhaler technology: formulation development." AAPS PharmSciTech 15, no. 2 (2014): 434-455. https://doi.org/10.1208/s12249-013-0063-x

[5] ROSS, DANNA L., and BRIAN J. GABRIO. "Advances in metered dose inhaler technology with the development of a chlorofluorocarbon-free drug delivery system." Journal of aerosol medicine 12, no. 3 (1999): 151-160. https://doi.org/10.1089/jam.1999.12.151

[6] Labiris, N. Renee, and Myrna B. Dolovich. "Pulmonary drug delivery. Part II: the role of inhalant delivery devices and drug formulations in therapeutic effectiveness of aerosolized medications." British journal of clinical pharmacology 56, no. 6 (2003): 600-612. https://doi.org/10.1046/i.1365-2125.2003.01893.x

[7] Stein, Stephen W., and Charles G. Thiel. "The history of therapeutic aerosols: a chronological review." Journal of aerosol medicine and pulmonary drug delivery 30, no. 1 (2017): 20-41. https://doi.org/10.1089/jamp.2016.1297

[8] Dolovich, Myrna. "New delivery systems and propellants." Canadian respiratory journal 6, no. 3 (1999): $290-295$. https://doi.org/10.1155/1999/682405

[9] Leach, Chet L., Patricia J. Davidson, Bruce E. Hasselquist, and Robert J. Boudreau. "Influence of particle size and patient dosing technique on lung deposition of HFA-beclomethasone from a metered dose inhaler." Journal of aerosol medicine 18, no. 4 (2005): 379-385. https://doi.org/10.1089/jam.2005.18.379

[10] Kleinstreuer, Clement, Huawei Shi, and Zhe Zhang. "Computational analyses of a pressurized metered dose inhaler and a new drug-aerosol targeting methodology." Journal of aerosol medicine 20, no. 3 (2007): 294-309. https://doi.org/10.1089/jam.2006.0617 
[11] Chan, John Gar Yan, Jennifer Wong, Qi Tony Zhou, Sharon Shui Yee Leung, and Hak-Kim Chan. "Advances in device and formulation technologies for pulmonary drug delivery." AAPS PharmSciTech 15, no. 4 (2014): 882-897.

https://doi.org/10.1208/s12249-014-0114-y

[12] Giri, Mahesh M., Kapileshwar Swain, and Sanjay Saha. "Metered Dose Inhaler: A Review." International Research Journal of Pharmaceutical and Applied Sciences 3, no. 1 (2013): 37-45.

[13] Lavorini, Federico, Giovanni A. Fontana, and Omar S. Usmani. "New inhaler devices-the good, the bad and the ugly." Respiration 88, no. 1 (2014): 3-15.

https://doi.org/10.1159/000363390

[14] Fadl, Ahmed, Jinbo Wang, and Zongqin Zhang. "Metered-dose inhaler efficiency enhancement: A case study and novel design." Inhalation toxicology 22, no. 7 (2010): 601-609.

https://doi.org/10.3109/08958371003599029

[15] Lewis, D. A., B. J. Meakin, and G. Brambilla. "New actuators versus old: reasons and results for actuator modifications for HFA solution MDIs." Respir Drug Deliv 1 (2006): 101-110.

[16] Abdullahi, Bala, Ahmed Elsayed, Raya Al-Dadah, Sa'ad Mahmoud, Abdel Fateh Mahrous, Nura Mu'az Muhammad, and Saidu Bello Abbakar. "Experimental and numerical investigation of thermosyphon heat pipe performance at various inclination angles." Journal of Advanced Research in Fluid Mechanics and Thermal Sciences 44, no. 1 (2018): 85-98.

[17] Hochrainer, Dieter, Hubert Hölz, Christoph Kreher, Luigi Scaffidi, Michael Spallek, and Herbert Wachtel. "Comparison of the aerosol velocity and spray duration of Respimat ${ }^{\circledR}$ Soft Mist ${ }^{\mathrm{TM}}$ inhaler and pressurized metered dose inhalers." Journal of aerosol medicine 18, no. 3 (2005): 273-282. https://doi.org/10.1089/jam.2005.18.273

[18] Cheng, Y. S., C. S. Fu, D. Yazzie, and Y. Zhou. "Respiratory deposition patterns of salbutamol pMDI with CFC and HFA-134a formulations in a human airway replica." Journal of aerosol medicine 14, no. 2 (2001): 255-266. https://doi.org/10.1089/08942680152484180

[19] Oliveira, Ricardo F., S. F. C. F. Teixeira, José C. Teixeira, Luís F. Silva, and Henedina Antunes. "pMDI sprays: Theory, experiment and numerical simulation." Advances in Modeling of Fluid Dynamics (2012): 300. https://doi.org/10.5772/46099

[20] Crosland, Brian Michael, Matthew Ronald Johnson, and Edgar Akio Matida. "Characterization of the spray velocities from a pressurized metered-dose inhaler." Journal of aerosol medicine and pulmonary drug delivery 22, no. 2 (2009): 85-98. https://doi.org/10.1089/jamp.2008.0687

[21] Oliveira, Ricardo F., Ana C. Ferreira, Senhorinha F. Teixeira, José C. Teixeira, and Helena C. Marques. "pMDI spray plume analysis: a CFD study." In Proceedings of the World Congress on Engineering, vol. 3. 2013.

[22] Mat, Mohamad Nur Hidayat, and Norzelawati Asmuin. "Optimizing Nozzle Geometry of Dry Ice Blasting Using CFD for the Reduction of Noise Emission." International Journal of Integrated Engineering 10, no. 5 (2018). https://doi.org/10.30880/ijie.2018.10.05.019

[23] Mat, Mohamad Nur Hidayat, Nor Zelawati Asmuin, Md Faisal Md Basir, Marjan Goodarzi, Muhammad Faqhrurrazi Abd Rahman, Riyadhthusollehan Khairulfuaad, Balasem Abdulameer Jabbar, and Mohd Shareduwan Mohd Kasihmuddin. "Influence of divergent length on the gas-particle flow in dual hose dry ice blasting nozzle geometry." Powder Technology 364 (2020): 152-158. https://doi.org/10.1016/i.powtec.2020.01.060

[24] Dunbar, Craig A., and Anthony J. Hickey. "Evaluation of probability density functions to approximate particle size distributions of representative pharmaceutical aerosols." Journal of aerosol science 31, no. 7 (2000): 813-831. https://doi.org/10.1016/S0021-8502(99)00557-1

[25] CLARK, ANDREW R. "MDIs: physics of aerosol formation." Journal of aerosol medicine 9, no. s1 (1996): S-19. https://doi.org/10.1089/jam.1996.9.Suppl 1.S-19

[26] Goswami, Mayank, Sanjeev Kumar, and Prabhat Munshi. "Correlation between numerical simulation and limited data experimental technique for estimation of nitrogen flowing in LMMHD loop." Flow Measurement and Instrumentation 46 (2015): 80-86.

https://doi.org/10.1016/j.flowmeasinst.2015.10.002

[27] Oliveira, Ricardo F., Senhorinha Teixeira, Luís F. Silva, José Carlos Teixeira, and Henedina Antunes. "Study of a pressurized metered-dose inhaler spray parameters in fluent." In Proceedings of the World Congress on Engineering, vol. 2. 2010.

[28] Syazwan F.M, Ahmad H.A, Ow C.S and Zulkifli A.G. "Effect of Inlet Slot Number on the Spray Cone Angle and Discharge Coefficient of Swirl Atomizer". Journal of Procedia Engineering 41, (2012): 1781-1786. https://doi.org/10.1016/i.proeng.2012.07.383 